\title{
Lipomatosis renal en donante cadáver
}

\author{
López López AI, Cao Avellaneda E, Maluff Torres A, López Cubillana P, Prieto González A, \\ Pérez Albacete M.
}

Servicio de Urología Hospital Universitario Virgen de la Arrixaca. Murcia. España.

Actas Urol Esp. 2006; 30 (6): 630-632

\section{RESUMEN}

\section{LIPOMATOSIS RENAL EN DONANTE CADÁVER}

Objetivo: Valorar la actitud a seguir ante el hallazgo de una o varias masas en la superficie renal durante la extracción de órganos de un donante cadáver.

Material y métodos: Donante cadáver varón de 56 años fallecido por hemorragia subaracnoidea y sin antecedentes urológicos de interés.

Resultados: El estudio anatomopatológico intraoperatorio de las masas renales informó de la naturaleza lipomatosa de las mismas, procediéndose al implante renal según la técnica habitual.

Conclusiones: El hallazgo de una masa en la superficie renal durante la extracción de órganos para trasplante constituye una indicación absoluta de biopsia previa al implante.

Palabras clave: Riñón. Trasplante renal. Angiomiolipoma. Donante vivo.

\section{ABSTRACT}

\section{KIDNEY LIPOMATOSIS IN A TRANSPLANTATION DONOR}

Objectives: The aim of this clinical note is to report one case of incidental superficial renal mass during an organ explantation.

Methods: The renal donor was a 56-years-old male patient death for subaracnoidea haemorrhage without urological history.

Results: The anatomopathologic intraoperative study of the renal masses informed about the fatty nature of the tissue, and the renal implantation was performed.

Conclusions: The find of a superficial renal mass during an organ explantatiation determine the necessity of a preoperative biopsy.

Keywords: Kidney. Kidney transplantation. Angiomyolipoma. Livivng donor.

$\mathrm{E}^{1}$ descubrimiento de una masa en la superficie del riñón durante la extracción renal de donante cadáver es un hallazgo relativamente infrecuente. En esta situación existe una indicación absoluta de biopsia intraoperatoria ya que, a pesar de que el primer diagnóstico a excluir es el de carcinoma, existen otras entidades que por su naturaleza benigna permiten que el órgano sea trasplantado sin riesgo para el receptor.

\section{CASO CLÍNICO}

Paciente varón de 51 años de edad con insuficiencia renal terminal de naturaleza no filiada, en programa de hemodiálisis, que ingresa para recibir injerto renal de donante cadáver. El donante era un varón de 56 años de edad fallecido por hemorragia subaracnoidea, sin antecedentes urológicos de interés.

La extracción renal bilateral se realizó sin incidencias, objetivándose durante la cirugía de banco dos tumores sólidos de aspecto lipomatoso que emergian de superficie renal. Se procedió a su enucleación (Fig. 1) y se llevó a cabo un estudio anatomopatológico intraoperatorio que reveló la naturaleza lipomatosa benigna de las masas, procediéndose a la sutura primaria de la base de 

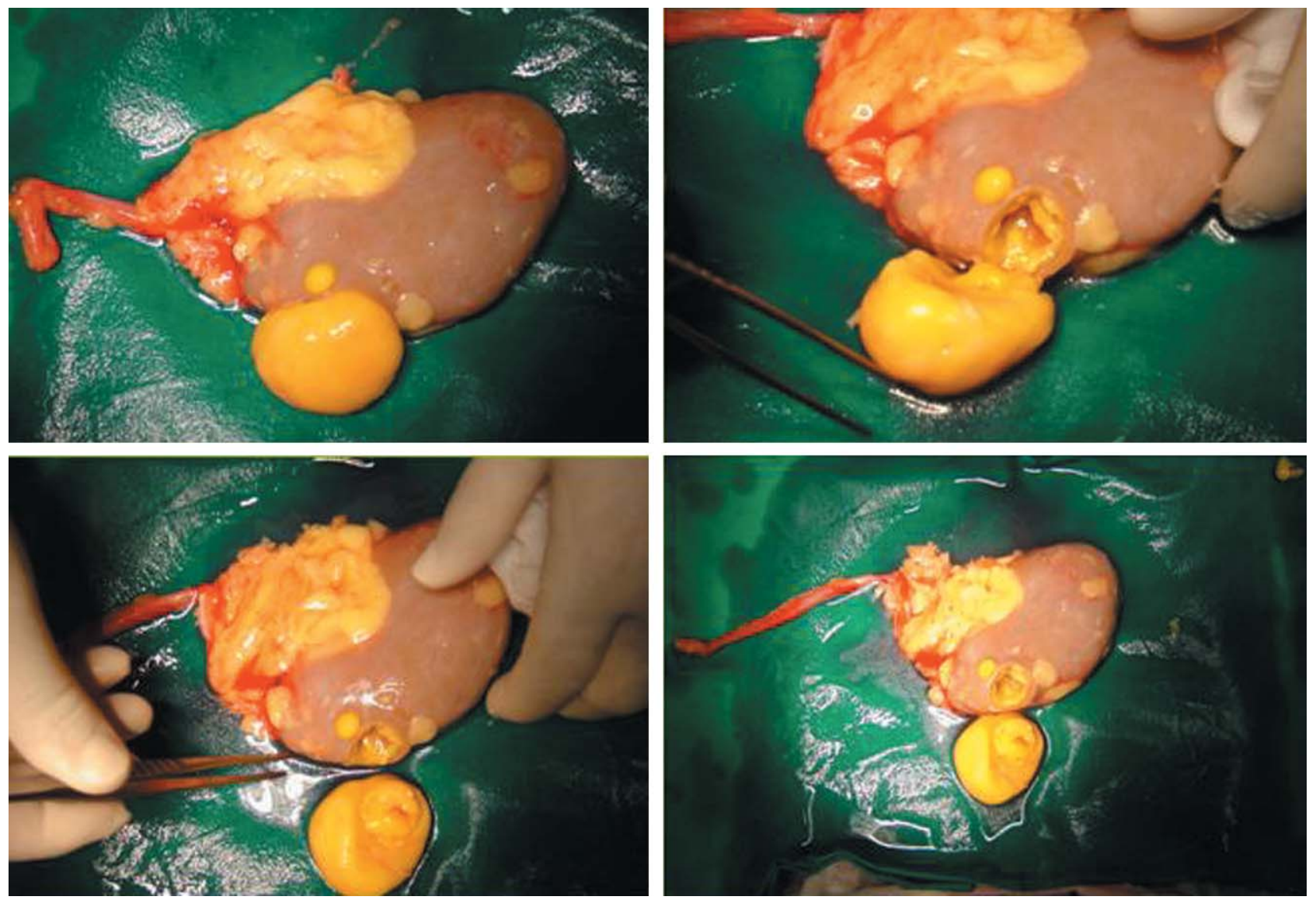

FIGURA 1: Enucleación de masas lipomatosas de la superficie renal

implantación tumoral y al implante del órgano que se realizó de forma habitual. El paciente presentó buena diuresis inicial con mejoría rápida de la función renal. La ecografía inicial mostró injerto normal con hidronefrosis grado I-II, sin colecciones perirrenales y con un IR de 0,7. El paciente fue dado de alta a los 11 días del implante con buena situación clínica y $\mathrm{Cr}$ de 1,8 $\mathrm{mg} \%$. Actualmente evoluciona favorablemente.

\section{DISCUSIÓN}

El descubrimiento de una masa en la superficie del riñón durante la extracción renal de donante cadáver es un hallazgo relativamente infrecuente ${ }^{1}$. Cualquier nódulo, independientemente de su tamaño o apariencia, que se localice en la superficie renal en la extracción de órganos para trasplante constituye una indicación de biopsia ${ }^{2}$.

Aunque sin duda el primer diagnóstico a excluir es el de carcinoma, el diagnóstico diferen- cial debe incluir otras entidades que por su naturaleza benigna permiten el aprovechamiento de los órganos para trasplante sin riesgo para el receptor.

Entre estas entidades se incluyen lipomas y angiomiolipomas, la ectopia adrenal y los leiomiomas o capsulomas ${ }^{2,3}$.

A pesar de que su coloración amarilla característica y su consistencia blanda confieren un aspecto macroscópico característico a los lipomas, este tipo de neoplasias benignas pueden entrañar cierta dificultad para su diagnóstico en biopsias por congelación, dada la dificultosa sección del tejido graso. Son depósitos de células adiposas maduras sin mitosis evidente que surgen de la cápsula renal o del tejido perirrenal. Se encuentran con mayor frecuencia en mujeres de edad madura.

Los angiomiolipomas son también neoplasias benignas, formadas por vasos, músculo liso y tejido adiposo. Se encuentran en alrededor de 45- 
80\% de pacientes con esclerosis tuberosa y en esta enfermedad de manera característica son bilaterales y asintomáticos. En pacientes sin esclerosis tuberosa, el angiomiolipoma puede ser unilateral y tiende a ser de mayor tamaño que el vinculado con la citada enfermedad. No existe diferencia histológica conocida entre las lesiones observadas en estas dos poblaciones ${ }^{4}$.

Los leiomiomas son tumores pequeños y poco comunes que se localizan característicamente en las áreas renales que contienen músculo liso como la cápsula o la pelvis renal. Se han descrito dos tipos. El grupo más frecuente engloba los leiomiomas menores de $2 \mathrm{~cm}$. que pueden ser únicos o múltiples y que no tienen significado clínico. Otro tipo de leiomioma descrito es un tumor más grande, por lo general solitario, que puede causar síntomas por compresión de estructuras adyacentes y cuya naturaleza se suele confirmar tras en el estudio anatomopatológico post nefrectomía.

Otra entidad benigna que a pesar de su escasa frecuencia debe ser tenida en cuenta en el diagnóstico diferencial es la ectopia adrenal. La localización de tejido adrenal fuera de su emplazamiento habitual tampoco es frecuente, pero debe ser incluido en el diagnóstico diferencial porque en algunas ocasiones la localización de este tejido fuera del riñón pudiera inducirnos a pensar que estamos ante metástasis de un posible carcinoma de células renales. Además cuando el foco ectópico se incluye en el parénquima renal su diagnóstico puede entrañar gran dificultad en ausencia de una cápsula que delimite el tejido renal del adrenal ${ }^{2,5}$.

Cuando el resultado de la biopsia de una masa renal objetivada en la extracción del órgano para su posterior implante, informa de una tumoración epitelial las características histológicas de la misma, su tamaño y las posibilidades de bilateralidad o metástasis cobran especial importancia. A este respecto la experiencia encontrada en la literatura es escasa ${ }^{6-8}$. La incidencia de car- cinoma de células renales en riñón trasplantado es baja y parece menor de la estimada en datos autópsicos. Cuando se presenta un caso de tumor de células renales en un injerto renal casi nunca es bien conocido si la trasformación maligna de las células estaba ya presente en el momento del trasplante o se desarrolló posteriormente con influencia del tratamiento inmunosupresor.

En cualquier caso no existe unanimidad en la conducta a seguir ante tumores renales de tamaño igual o menor a $0,5 \mathrm{~cm}$ y en lo que respecta al aprovechamiento de otros órganos como hígado o corazón en caso de donante multiorgánico con tumores renales diagnosticados tras el implante.

\section{REFERENCIAS}

1. Hetet J.F, Rigaud J, Blancho G, Renaudin K, Bouchot O, Karam G. Transplantation rénale après exérèse d’un angiomyolipome sur un greffon issu de donneur vivant. Prog.Urol. 2004;14:205-206.

2. Carrera M, González C, Condom E, Bernat R.. Biopsia del donante en el trasplante renal. Revista Española de Patologia;2002:35(3):295-300.

3. Crawford J.M, Cotran R.S. Tumores renales benignos. En: Patología estructural y funcional. Interamericana-McGrawHill. 2000;20:1090-1093.

4. Dreicer R, Williams R.D. Neoplasias del parénquima renal. Urologia General de Smith. Ed Manual Moderno. México 2001;22:379-397.

5. WuT, Bihrle R, Yum MN. Heterotopic adrenal cortical adenoma masquerading as metastatic renal cell carcinoma. J.Urol. 1999;161:595-596.

6. Heritier P, Bizrane M, Farcot M. Trasplantation and tumors of the kidney. J.Urol. 1991;96(3):167-168.

7. Chen A, Scherr D, Eid F. Renal transplantation after in vivo excision of an angyomiolipoma from a living unrelated kidney donor. J of Urol. 2000;163:1859.

8. Fritsche L, Budde K, Rogalla. Succesful living related kidney transplantation despite renal angiomyolipoma in situ. $J$ of Urol. 1999, 162:480.

Dra. A.I. López López

e-mail: llanais@hotmail.com

(Trabajo recibido el 24 de junio de 2006) 